\title{
Is it feasible and effective to provide faculty development programs online for clinical teachers?
}

\author{
Ji Hyun $\mathrm{Im}^{1,2}$, Ju Whi Kim ${ }^{3}$, Wan Beom Park ${ }^{4}$, Ilkyu Han ${ }^{1,5}$, Seung Hee Lee ${ }^{1,2}$, Jwa Seop Shin ${ }^{1,2}$ and \\ Hyun Bae Yoon ${ }^{1,3}$
}

\author{
${ }^{1}$ National Teacher Training Center for Health Personnel, ${ }^{2}$ Department of Medical Education, ${ }^{3}$ Office of Medical \\ Education, and Departments of ${ }^{4}$ Internal Medicine and ${ }^{5}$ Orthopaedic Surgery, Seoul National University College \\ of Medicine, Seoul, Korea
}

Purpose: Seoul National University College of Medicine operates a faculty development program for clinical teachers at multiple affiliated teaching hospitals. In 2020, the program was moved online due to coronavirus disease 2019. The purpose of this study was to determine whether it is feasible and effective to provide faculty development programs online in terms of clinical teachers' participation and satisfaction in comparison with offline programs.

Methods: Clinical teachers participated in the clinical teaching methods programs offline in 2019 and online in 2020. We analyzed participation rate and satisfaction level. All surveys items were rated on a 5-point Likert scale. We also interviewed instructors about the advantages and drawbacks of the online program.

Results: The participation rate of the online program (89.5\%) was significantly higher than that of the offline program (67.8\%). The overall satisfaction level for the online program (4.37) was similar to that for the offline program (4.50).

Conclusion: Faculty development programs online are feasible and effective in medical education. We need to design training content that fits online programs, consider various online training methods to reinforce the strengths of online programs, and support participants to make good use of these programs.

Key Words: Teacher training, Staff development, Online education, Clinical teaching, Clinical teacher

\section{Introduction}

Clinical teaching is the most important component of basic medical education. Based on the knowledge learned from lectures, students acquire basic clinical skills and communication skills for patient care, and understand the organization of the hospital where they will work in the future. Clinical teaching for students is unpredictable and unstructured in clinical settings; therefore, both students and clinical teachers need to be familiar with the objectives and methods of clinical teaching. Clinical teachers should also provide opportunities and feedback for students to participate in clinical teaching [1]. This is important because students' learning experience, which depend on choices made in clinical instruction, have a significant impact on their lives as doctors afterwards.

The importance of clinical teaching and the role of clinical teachers underscores the importance of faculty development programs for clinical teachers. Faculty
Received: April 15, 2021 • Revised: April 28, 2021 • Accepted: April 28, 2021 Corresponding Author: Hyun Bae Yoon (https://orcid.org/0000-0003-4367-5350) National Teacher Training Center for Health Personnel, Seoul National University College of Medicine, 71 Ihwajang-gil, Jongno-gu, Seoul 03087, Korea Tel: +82.2.740.8418 Fax: +82.2.745.6373 email: hbyoon@snu.ac.kr
Korean J Med Educ 2021 Jun; 33(2): 139-145

https://doi.org/10.3946/kjme.2021.195

eISSN: 2005-7288

(C) The Korean Society of Medical Education. All rights reserved. This is an open-access article distributed under the terms of the Creative Commons Attribution Non-Commercial License (http:// creativecommons.org/licenses/by-nc/3.0/), which permits unrestricted non-commercial use, distribution, and reproduction in any medium, provided the original work is properly cited. 
development can provide a conceptual framework for teaching, help clinical teachers adopt and adapt specific teaching behaviors to real clinical settings, and introduce teachers to a community of medical instructors interested in furthering clinical teaching and learning [2]. Formal faculty development programs in clinical teaching may be desirable if a clinician wishes to be an effective clinical teacher. Nevertheless, most clinical teachers have not been trained to teach, and faculty development for clinical teachers is undermined by poor attendance, inadequate knowledge transfer, and unsustainability [3]. Therefore, faculty development programs should be designed to account for the characteristics of clinical teachers and the clinical environment in which they work.

Seoul National University College of Medicine has emphasized the importance of clinical teaching and has developed related faculty development programs. As the clinical teaching environment changes, the concept of site-specific teaching has emerged as important in establishing the learning objectives for each setting, such as the clinic, the inpatient ward, and the operating room [4]. In addition, new demands for strategies to enhance faculty development programs in clinical teaching have emerged. For that reason, Seoul National University College of Medicine developed a new clinical teaching training methods program in 2018. The goal of the program is to foster the ability to effectively conduct hands-on training in a variety of clinical situations. This program is for clinical teachers; in particular, teachers in charge of training and new teachers are required to participate. Since clinical teaching is conducted at three hospitals (the main hospital and two branch hospitals), the program is held at each site separately in order to increase accessibility and the participation rate. In 2020, when coronavirus disease 2019 (COVID-19) hit, we moved the program online.
This study aimed to compare the participation rate and satisfaction level of participants who attended offline and online programs for clinical teaching training methods at Seoul National University College of Medicine, and to analyze the advantages and drawbacks of the online program.

\section{Methods}

\section{Comparison of the offline program in 2019 and the online program in 2020}

\section{1) Offline program in 2019}

In 2019, the clinical teaching training methods program was held for 3 hours, including meal times, in the seminar rooms of each of the three hospitals as a face-to-face program. It covered content including the purpose and advantages of clinical teaching; teaching methods and effective feedback in the clinical setting; practical tips in the outpatient clinic, inpatient ward, and operating room; and a summary of effective clinical teaching methods through lectures, discussions and practice sessions. Instructors and facilitators, who were clinical teachers at on-campus hospitals, designed the program and conducted the lectures. In the practice sessions, pre-recorded clinical teaching case videos and scenarios were shown and participants were asked to evaluate and discuss. In addition, they were asked to role-play in small groups as clinical teachers and students. They used flip charts and paper worksheets for group activities.

\section{2) Online program in 2020}

In 2020, the non-face-to-face program used online platforms for 2.5 hours. The contents and the instructor were almost the same as the offline program. However, the program was delivered through an online platform, 
Zoom (Zoom Video Communications Inc., San Jose, USA). Zoom is a convenient online tool that supports online meetings or trainings. Lectures were given on the content of the offline lectures through real-time video, and Zoom's small group function was used to divide participants into groups with a tutor in each group to enable real-time discussions. The practice sessions were the same, except for the role-play. We produced one more video about the one-minute preceptor, and further discussion was held about this case instead of the role play. Participants used online files and screen sharing or chatting functions for group activities.

\section{Comparison of participation and satisfaction}

Participants' participation and satisfaction for online program in 2020 were compared with offline program in 2019.

\section{1) Participation}

Participation was compared between the offline and online programs using the attendance rate. At the offline programs in 2019, when the teachers entered the seminar room, they signed the attendance sheet only once. Therefore, regardless of how long they were actually present, they were considered to have completed the program. For the online program in 2020, attendance was checked by the online real-time video lecture access history and the face shown on the screen. Therefore, completion was evaluated using accurate access records on the online platform. The completion criterion was presence during $90 \%$ of the online sessions.

\section{2) Satisfaction}

Satisfaction with the program was analyzed through a survey in both the offline and online programs. The survey consisted of a common questionnaire and a lecture-specific questionnaire. The common questionnaire was composed of four questions, including satisfaction with the overall program, insight into new knowledge, content of the lecture material, and intention to recommend the program to others. The lecturespecific questionnaire was composed of eight questions, including satisfaction and the utilization of each of the four modules: the purpose and advantages of clinical teaching; the teaching method and effective feedback in the clinical setting; practical tips in the outpatient clinic, the inpatient ward, and operating room; and summary of effective clinical teaching methods. They responded to items using a 5-point Likert scale, matching with options including "very unsatisfied (1 point)", "unsatisfied (2 points)", "neutral (3 points)", "satisfied (4 points)", and "very satisfied (5 points)".

\section{Satisfaction with the online program}

We surveyed the clinical teachers who attended the program in 2020 about their online program satisfaction. The survey was composed of eight questions, including the appropriateness of the training content and methods, interest in self-improvement and motivation for learning, equal quality of training to that of the offline program, value in terms of time and effort invested, sufficient guidance before online participation, immediate communication and feedback, the effectiveness of interactions with instructors, and smooth participation and progress. They rated their responses on a 5-point Likert scale, with options including "strongly disagree (1 point)", "disagree (2 points)", "neutral (3 points)", "agree (4 points)", and "strongly agree (5 points)".

\section{The advantages and drawbacks of the offline and online programs}

We held an interview with the instructors and facilitators of the programs.

\section{Data analysis}

The offline program in 2019 was attended by 40 
participants, of whom 36 responded to the survey. The online program in 2020 was attended by 51 participants, of whom 43 responded to the survey. This study was approved by the Institutional Review Board (IRB) of Seoul National University College of Medicine (IRB approval no., E-2102-099-1197). The requirement for written informed consent from the teachers was waived due to the anonymous and retrospective nature of this study.

The collected data were statistically analyzed using Excel 2019 (Microsoft Office Professional Plus; Microsoft Corp., Redmond, USA) and IBM SPSS for Windows ver. 25.0 (IBM Corp., Armonk, USA). Participants' participation and satisfaction with the program were compared and tested with the independent t-test for comparison of means. The responses to the interview of instructors were subjected to content analysis.

\section{Results}

\section{Comparison of participation in the program}

Fifty-nine clinical teachers registered for the offline program in 2019, of which 19 did not attend. Therefore, 40 participants attended. Fifty-seven clinical teachers registered for the online program in 2020, of which six did not attend. Fifty-one participants attended and 49

Table 1. Comparison of Participation in the Program

\begin{tabular}{lcc}
\hline \multicolumn{1}{c}{ Format (year) } & Offline (2019) & Online (2020) \\
\hline Registrants & 59 & 57 \\
No-show & $19(32.2)$ & $6(10.5)$ \\
Attendees & $40(67.8)$ & $51(89.5)$ \\
Completion & $40(67.8)^{\text {a) }}$ & $49(86.0)$ \\
\hline
\end{tabular}

Data are presented as number or number $(\%)$.

${ }^{a)}$ For the offline program, completion was equated to attendance (i.e., there was no separate measure for completion). participants completed the program. The participants' average attendance rate was $67.8 \%$ for the offline program and $89.5 \%$ for the online program. The completion rate was $67.8 \%$ for the offline program and $86.0 \%$ for the online program (Table 1).

\section{Comparison of satisfaction with the program}

No statistically significant differences were found between the participants who attended the offline program in 2019 and those who attended the online program in 2020 in terms of all items evaluating satisfaction (Table 2).

\section{Satisfaction of with the online program}

The participants who attended the online program in 2020 stated that they were satisfied, with mean scores of 4.16 or higher for all questions. The average satisfaction level was the highest (4.51) for the item "Interactions with instructors were effective in real-time video lectures (Zoom)," while the second-highest scores (4.49 each) were found for the items "The online program generated interest in self-improvement and motivation for learning" and "The value of the online program corresponded to the time and effort I invested (Table 3)."

\section{Advantages and drawbacks of the offline and online programs}

Instructors responded the advantages and drawbacks of the online programs by comparing offline programs. As an advantage of the online program, the instructors first stated that participants' preparation for the program was high because almost all participants had clinical teaching training experience. Therefore, many participants could actively participate. This advantage was also present for the offline program. Second, physical opportunity costs such as travel time, distance, and assistant staff were reduced in the online program, 
Table 2. Comparison of Satisfaction with the Program

\begin{tabular}{|c|c|c|c|c|}
\hline \multirow{2}{*}{ Question } & \multicolumn{2}{|c|}{ Format } & \multirow{2}{*}{ t-value } & \multirow{2}{*}{$\mathrm{p}$-value } \\
\hline & Offline $(n=36)$ & Online $(n=43)$ & & \\
\hline \multicolumn{5}{|l|}{ Common questionnaire } \\
\hline I am overall satisfied with this program. & $4.50 \pm 0.70$ & $4.37 \pm 0.58$ & 0.89 & 0.38 \\
\hline $\begin{array}{l}\text { I was able to broaden my knowledge and gain insights into new knowledge } \\
\text { through this program. }\end{array}$ & $4.56 \pm 0.69$ & $4.37 \pm 0.66$ & 1.21 & 0.23 \\
\hline $\begin{array}{l}\text { I was able to get help understanding and participating in this program through } \\
\text { the lecture materials. }\end{array}$ & $4.42 \pm 0.69$ & $4.47 \pm 0.55$ & -0.35 & 0.73 \\
\hline I would recommend this program to others. & $4.56 \pm 0.73$ & $4.40 \pm 0.66$ & 1.02 & 0.31 \\
\hline \multicolumn{5}{|l|}{ Lecture-specific questionnaire } \\
\hline \multicolumn{5}{|l|}{ Are you satisfied with the content of the program? } \\
\hline The purpose and advantages of clinical teaching & $4.50 \pm 0.74$ & $4.49 \pm 0.69$ & 0.07 & 0.94 \\
\hline Teaching methods and effective feedback in the clinical setting & $4.64 \pm 0.64$ & $4.65 \pm 0.48$ & -0.10 & 0.92 \\
\hline Practical tips in the outpatient clinic, inpatient ward, and operating room & $4.69 \pm 0.58$ & $4.63 \pm 0.49$ & 0.56 & 0.58 \\
\hline Summary of effective clinical teaching methods & $4.56 \pm 0.73$ & $4.65 \pm 0.48$ & -0.67 & 0.51 \\
\hline \multicolumn{5}{|l|}{ Do you expect this program to help you apply the content in practice in the future? } \\
\hline The purpose and advantages of clinical teaching & $4.33 \pm 0.83$ & $4.49 \pm 0.70$ & -0.90 & 0.37 \\
\hline Teaching methods and effective feedback in the clinical setting & $4.61 \pm 0.73$ & $4.67 \pm 0.47$ & -0.47 & 0.64 \\
\hline Practical tips in the outpatient clinic, inpatient ward, and operating room & $4.64 \pm 0.59$ & $4.63 \pm 0.54$ & 0.09 & 0.93 \\
\hline Summary of effective clinical teaching methods & $4.58 \pm 0.69$ & $4.70 \pm 0.46$ & -0.85 & 0.40 \\
\hline
\end{tabular}

Data are presented as mean \pm standard deviation, unless otherwise stated. Items were rated on a 5-point Likert scale.

Table 3. Satisfaction with the Online Program

\begin{tabular}{lc}
\hline \multicolumn{1}{c}{ Question } & Mean $\pm S D$ \\
\hline Interactions with instructors were effective in real-time video lectures (Zoom) & $4.51 \pm 0.63$ \\
The online program generated interest in self-improvement and motivation for learning & $4.49 \pm 0.55$ \\
The value of the online program corresponded to the time and effort I invested & $4.49 \pm 0.59$ \\
The training content and methods of the online program were appropriate. & $4.42 \pm 0.54$ \\
Immediate communication and feedback were made, including questions and answers, when participating in the online programs. & $4.42 \pm 0.63$ \\
The participation and progress of real-time video lectures (Zooms) was smooth. & $4.37 \pm 0.76$ \\
Compared to offline programs, the quality of training was the equal. & $4.26 \pm 0.76$ \\
Prior guidance was sufficiently provided before online program participation. & $4.16 \pm 0.92$ \\
\hline
\end{tabular}

Items were rated on a 5-point Likert scale.

SD: Standard deviation.

whereas the offline program was inconvenient in terms of time and space. Third, the atmosphere of the online program was better than offline. In particular, the junior participants felt less pressure and stated that the atmosphere enabled a freer exchange of opinions than was possible in the offline program.

Nonetheless, the instructors pointed out some drawbacks of the online program. First, the content of offline program had to be reconstructed to be suitable for the online platform, and there were also restrictions on some practice components, such as role-play conducted offline. Second, the instructors were not familiar with the online platform, which caused anxiety, and they needed extensive preparation time such as prerehearsals. Third, mental fatigue was rather higher than was the case for the offline program, because the instructors were concerned that they would need to deal with unexpected situations such as technical problems. In fact, technical problems (e.g., difficulty accessing the platform) often occurred. Finally, some things can only 
be shown face to face. It is difficult for instructors to recognize participants' immediate responses or to show emotions such as passion. Offline programs may be more advantageous in this regard.

When asked about their overall opinion on online programs, they responded that there was no significant difference between offline and online settings for activities such as lectures and discussions. They stated that they were worried at first, but ultimately felt that it was "worth doing" after careful practice and repeated sessions.

\section{Discussion}

The participation rate of the clinical teaching methods program was higher for the online program than for the offline program, although the training start time and learning time were the same. The number of no-shows also decreased significantly. This likely occurred because the online program could be accessed anytime and anywhere with an internet connection and a suitable device, and busy clinical teachers did not have the burden of needing to go to the training place. In addition, the online platform had the advantage of being able to manage learning history (e.g., attendance). In the offline program, the analysis of the completion rate was limited because there was no way to determine whether participants were late to the training program or left in the middle of a session.

Satisfaction with the program showed no statistically significant differences between offline and online programs. However, in the common questionnaire on satisfaction, the offline program had a slightly higher average score than online program. It is expected that participants will have a greater sense of satisfaction and belonging when they take part in a face-to-face program. In the lecture-specific questionnaire, the scores for both satisfaction and utilization were almost the same or higher for the online program. This means that there was no problem with content delivery and acquisition of the online program.

Online program satisfaction in 2020 was at a high level. This shows that clinical teachers can interact with instructors smoothly and receive training content well, even in an online setting. These results suggest that, despite concerns compared to offline programs, the online program was successful and that online faculty development holds promising possibilities. The possibility of online faculty development was documented in earlier studies prior to the COVID-19 era [5]. In particular, the constraints that arise when there are multiple affiliated teaching hospitals at different locations can be overcome through online education methods. Moreover, online faculty development programs help to create an atmosphere where people can freely express their opinions during discussions or group activities. A study on online education for students showed that it was rather difficult for students to interact with their peers [6]. However, since clinical teachers have top-down relationships in hospitals, this study seems to have shown better interactions online. Rapport had already been formed between the instructors and participants, so they felt that the atmosphere was safe; it was easy to turn each camera on and hold smooth discussions. These findings are implying that online faculty development is relatively easier than online student education.

For online faculty development to work well, we should complement the drawbacks of offline programs and strengthen the advantages of online programs. Programs should also be well-designed in recognition of online constraints and based on a detailed design of lectures, practices, and group activities. Directions for 
designing well-balanced offline and online programs after COVID-19 should also be considered. Based on other articles, online faculty development appears to be more successful when it meets the relevant needs of the course, promotes communication and interaction, and provides time to complete course activities [7]. In order to implement online education well, we will need to have guidelines about the design and teaching of online courses for instructors and facilitators [8].

In conclusion, our study analyzed participation and satisfaction in faculty development programs offline and online, and aimed to determine the possibility of online faculty development for clinical teachers. The participation rate in the online program was higher than that of the offline program. Overall satisfaction with the online program was also as high as offline, and satisfaction with the operation of the online program itself was also high. Advantages in online interactions resulted from the novel aspects of new technology and open atmosphere, a meaningful factor in online faculty development. Therefore, various online teaching methods and tools should be considered for online faculty development, and steps should be taken to support participants to make good use of them.

\section{ORCID:}

Ji Hyun Im: https://orcid.org/0000-0002-9573-1695;

Ju Whi Kim: https://orcid.org/0000-0001-8011-3547;

Wan Beom Park: https://orcid.org/0000-0003-0022-9625; Ilkyu Han: https://orcid.org/0000-0001-9841-3775;

Seung Hee Lee: https://orcid.org/0000-0001-8672-5253; Jwa Seop Shin: https://orcid.org/0000-0002-6251-3616; Hyun Bae Yoon: https://orcid.org/0000-0003-4367-5350

Acknowledgements: We would like to express our appreciation for all the participants in this clinical teaching methods program and all staff members of the
Seoul National University College of Medicine.

Funding: No financial support was received for this study.

Conflicts of interest: No potential conflict of interest relevant to this article was reported.

Author contributions: HBY conceived and designed the study. JHI drafted the initial version of the manuscript and analyzed the data. WBB and JHK provided critical comments. All authors discussed and approved the final manuscript.

\section{References}

1. Spencer J. Learning and teaching in the clinical environment. BMJ. 2003;326(7389):591-594.

2. Ramani S, Leinster S. AMEE Guide no. 34: teaching in the clinical environment. Med Teach. 2008;30(4):347-364.

3. Cantillon P, Dornan T, De Grave W. Becoming a clinical teacher: identity formation in context. Acad Med. 2019;94(10):1610-1618.

4. Distlehorst LH, Dunnington G, Folse R. Teaching and learning in medical and surgical education: lessons learned for the 21st century. Mahwah, USA: Erlbaum; 2000.

5. Park JH, Son JY, Yoo NJ, Kim S. A review on usage and effectiveness of e-learning in medical education. Korean J Med Educ. 2010;22(2):91-100.

6. Lee SJ, Park J, Lee YJ, Lee S, Kim WH, Yoon HB. The feasibility and satisfaction of an online global health education course at a single medical school: a retrospective study. Korean J Med Educ. 2020;32(4):307-315.

7. Cook DA, Steinert Y. Online learning for faculty development: a review of the literature. Med Teach. 2013;35(11):930-937.

8. Rhim HC, Han H. Teaching online: foundational concepts of online learning and practical guidelines. Korean J Med Educ. 2020;32(3):175-183. 